\title{
Early severe impairment of hematopoietic stem and progenitor cells from the bone marrow caused by CLP sepsis and endotoxemia in a humanized mice model
}

Tomasz Skirecki ${ }^{1,2 *}$, Jerzy Kawiak ${ }^{1}$ Eugeniusz Machaj ${ }^{3}$, Zygmunt Pojda $^{3}$, Danuta Wasilewska ${ }^{4}$, Jarosław Czubak ${ }^{5}$ and Grażyna Hoser ${ }^{4}$

\begin{abstract}
Introduction: An effective immune response to severe bacterial infections requires a robust production of the innate immunity cells from hematopoietic stem and progenitor cells (HSPCs) in a process called emergency myelopoiesis. In sepsis, an altered immune response that leads to a failure of bacterial clearance is often observed. In this study, we aimed to evaluate the impact of sepsis on human HSPCs in the bone marrow (BM) microenvironment of humanized mice subjected to acute endotoxemia and polymicrobial sepsis.

Methods: Humanized mice (hu-NSG) were generated by transplanting NOD.Cg-Prkdc/scidIL2ry (NSG) mice with the human cord blood CD34 $4^{+}$cells. Eight weeks after the transplantation, hu-NSG mice were subjected to sepsis induced by endotoxemia—Escherichia coli lipopolysaccharide (LPS)—or by cecal ligation and puncture (CLP). Twenty-four hours later, HSPCs from BM were analyzed by flow cytometry and colony-forming unit (CFU) assay. CLP after inhibition of Notch signaling was also performed. The effects of LPS on the in vitro proliferation of CD34 $4^{+}$cells from human BM were tested by CellTrace Violet dye staining.

Results: The expression of Toll-like receptor 4 receptor was present among engrafted human HSPCs. Both CLP and endotoxemia decreased (by $43 \%$ and $37 \%$ ) cellularity of the BM. In addition, in both models, accumulation of early $\mathrm{CD}_{4} 4^{+} \mathrm{CD} 38^{-} \mathrm{HSCS}$ was observed, but the number of $\mathrm{CD} 34^{+} \mathrm{CD} 38^{+}$progenitors decreased. After CLP, there was a 1.5 -fold increase of proliferating CD34 ${ }^{+} \mathrm{CD} 38^{-} \mathrm{Ki}-67^{+}$cells. Moreover, CFU assay revealed a depressed (by $75 \%$ after LPS and by $50 \%$ after CLP) production of human hematopoietic colonies from the BM of septic mice. In contrast, in vitro LPS stimulated differentiation of $\mathrm{CD}_{3} 4^{+} \mathrm{CD} 38^{-} \mathrm{HSC}$ but did not induce proliferation of these cells in contrast to the $\mathrm{CD}_{3} 4^{+} \mathrm{CD} 38^{+}$progenitors. CLP sepsis modulated the BM microenvironment by upregulation of Jagged-1 expression on non-hematopoietic cells, and the proliferation of HSCs was Notch-dependent.
\end{abstract}

Conclusions: CLP sepsis and endotoxemia induced a similar expansion and proliferation of early HSCs in the BM, while committed progenitors decreased. It is suggestive that the Notch pathway contributed to this effect. Targeting early hematopoiesis may be considered as a viable alternative in the existing arsenal of supportive therapies in sepsis.

\footnotetext{
* Correspondence: tskirecki@gmail.com

${ }^{1}$ Department of Flow Cytometry, The Center of Postgraduate Medical

Education, Marymoncka 99/103, 01-813 Warsaw, Poland

${ }^{2}$ Department of Anesthesiology and Intensive Care Medicine, The Center of

Postgraduate Medical Education, Czerniakowska 231, 00-416 Warsaw, Poland

Full list of author information is available at the end of the article
}

(c) 2015 Skirecki et al. Open Access This article is distributed under the terms of the Creative Commons Attribution 4.0 International License (http://creativecommons.org/licenses/by/4.0/, which permits unrestricted use, distribution, and reproduction in any medium, provided you give appropriate credit to the original author(s) and the source, provide a link to the Creative Commons license, and indicate if changes were made. The Creative Commons Public Domain Dedication waiver (http://creativecommons.org/publicdomain/zero/1.0/) applies to the data made available in this article, unless otherwise stated. 


\section{Introduction}

Despite the continuous progress in critical care medicine and anti-microbial therapies, sepsis and septic shock remain a serious health-care problem worldwide. The morbidity due to sepsis reaches $50-95$ cases per 100,000 citizens in the USA annually [1], and the average mortality rates are high: $41 \%$ in Europe and $28 \%$ in the USA [2]. It has been speculated in recent years that the complex pathophysiology of sepsis coupled with the highly heterogeneous makeup of patients with sepsis has hindered successful development of specific anti-sepsis drugs. Thus far, the major improvement in outcome has been achieved by introduction of the Sepsis Surviving Campaign Guidelines in 2004 [3].

The central role of immune system disturbances in sepsis pathophysiology has been well recognized, and an effort was made to comprehensively categorize those disturbances. At the cellular level, fight against an infection requires massive production of immunecompetent cells of the innate immunity. This process is called emergency myelopoiesis and involves a robust proliferation of hematopoietic progenitors and progression of dormant hematopoietic stem cells (HSCs) into the cell cycle [4]. The emergency hematopoiesis represents a physiological response of the immune system to infections that is governed by (a) direct stimulation of progenitor cells via Toll-like receptors (TLRs) [5], (b) production of growth factors and cytokines by the bone marrow (BM) niche-forming cells and mature hematopoietic cells (like granulocyte colony-stimulating factor, or G-CSF) [6], and (c) paracrine effects of TLR-activated HSCs [7]. To maintain hematopoietic homeostasis, a balance between self-renewal and differentiation of 'true' HSCs must be maintained. It was shown in the mouse that chronic inflammatory stimulation leads to an exhaustion of HSCs in a model of multiple low-dose lipopolysaccharide (LPS) injections [8]. Also, TLR stimulation was reported to skew HSC differentiation toward myeloid lineages [5]. Given that existing studies point out that many patients with sepsis die with signs of compromised immune defense and ongoing infections [9], characterization of the emergency myelopoiesis dynamics in sepsis is highly warranted. Although patients with sepsis typically present with a robust blood leukocytosis, marked leukopenia has been frequently reported in other subjects with sepsis. In fact, both reactions are included in the diagnostic criteria of sepsis [10]. It is currently not known whether leukopenia is a consequence of the failure of HSC response or an inadequate signaling in the BM microenvironment. Yet, to date, no clinical studies have characterized distribution of the BM stem and progenitor cells and their potential modulation by sepsis syndromes. The existing data on hematopoiesis under infectious conditions come exclusively from experimental models of infections and sepsis in mice. Intriguingly, the data regarding HSCs and their progeny are conflicting. Whereas the model of cecum ligation and puncture (CLP) septic peritonitis led to an expansion of both long-term HSCs (LT-HSCs) and short-term HSCs (STHSCs) [11], Pseudomonas aeruginosa sepsis and LPS endotoxemia expanded only the LT-HSCs. However, LT-HSC functionality was compromised as shown in the repopulating experiments [12]. Similarly, an intravenous injection of heat-killed Escherichia coli was demonstrated to expand HSCs at the expense of myeloid progeny [13]. Although several mechanisms of the HSC expansion in those conditions have been proposed (e.g., proliferation of HSCs, block of differentiation, and 'de-differentiation' of committed progenitors), it remains to be evaluated whether similar processes occur in human sepsis.

The relevance of used mouse models of critical care diseases has been recently vigorously discussed [14]. The recently developed humanized mice models that rely on hu-HSC transplantation offer a high clinical relevance to multiple investigative and mechanistic approaches in those mice [15]. For example, CLP sepsis in humanized mice has already been shown to mimic some of the features of immune disturbances observed in patients with sepsis, including production of human cytokines and apoptosis of human CD3 lymphocytes [16]. After intravenous transplantation, hu-HSCs home to murine BM in an SDF-1-CXCR4-dependent manner [17] and recreate histological positioning within the bone structure similar to the one present in humans [18]. In regard to recapitulation of clinical sepsis syndromes, several animal models have been developed and used in the last decades. One of the most common approaches is an injection of bacterial LPS. Although it is currently not considered an appropriate simulation of sepsis [19], it nevertheless constitutes a simple and reproducible experimental system which evokes a strong and transient release of inflammatory mediators. In contrast, CLP has been deemed much more clinically relevant given that it reproduces many aspects of human septic peritonitis [19]. Although various endpoints were previously compared in those two models (i.e., LPS and CLP), a comparison of endotoxemia and sepsis impact upon the hematopoietic stem and progenitor cells (HSPCs) in the BM microenvironment in a humanized mouse model system has been never attempted.

In the present study, we aimed to investigate the modulatory effects of CLP sepsis and LPS endotoxemia on human HSPCs in the BM of the NOD.Cg-Prkdc/scidIL2ry (NSG) humanized mouse model. Specifically, we set out (1) to characterize potential changes in the phenotypes or markers (or both) of proliferation of the 
grafted human cells and (2) to examine the proliferation capacity of the grafted human hematopoietic progenitor cells (HPCs).

\section{Methods}

\section{Human umbilical cord blood $\mathrm{CD}_{3} 4^{+}$cells}

Human umbilical cord blood (UCB) samples were processed in accordance with the procedures approved by the Institutional Review Board of the Maria SklodowskaCurie Memorial Cancer Center and Institute of Oncology. The UCB units from healthy donor mothers were obtained with their informed consent. The UCB (30-50 ml) was drained with the standard Baxter set with citrate volume reduced to $23 \mathrm{ml}$. Numbers of white blood cells and mononuclear cells were estimated by using a Sysmex 820 semiautomatic hematological analyzer (Sysmex Co., Kobe, Japan). Next, blood diluted 1:1 with phosphate-buffered saline (PBS) was applied to Ficoll (Invitrogen Ltd, Paisley, UK)-Uropoline (Polpharma SA, Starogard Gdanski, Poland) of density of $1.077 \mathrm{~g} / \mathrm{ml}$ and centrifuged for $40 \mathrm{~min}$ at $400 \times g$ at $4{ }^{\circ} \mathrm{C}$. Isolated cells were frozen in liquid nitrogen in Dulbecco's modified Eagle's medium (Invitrogen Ltd) containing $50 \%$ inactivated fetal bovine serum (FBS) (Pan-Biotech GmbH, Aidenbach, Germany) and $10 \%$ dimethyl sulfoxide (DMSO) (Sigma-Aldrich, St. Louis, MO, USA).

Enrichment of human HSCs was performed by isolation of $\mathrm{CD}^{+} 4^{+}$cells from thawed UCB mononuclear cells. CD34 ${ }^{+}$were separated by the positive immune separation method by using an EasySep CD34 kit (Stemcell Technologies, Vancouver, BC, Canada) in accordance with the protocol of the manufacturer. Purity of the isolated cells was evaluated by flow cytometry after staining with anti-CD45 FITC/anti-CD34 PE antibody cocktail (BD Biosciences, San Jose, CA, USA). Each isolation resulted in $\mathrm{CD}_{3} 4^{+}$cell purity of more than $90 \%$.

\section{Mice and transplantation of $\mathrm{CD} 34^{+}$cells}

NSG breeding pairs were obtained from The Jackson Laboratory (Bar Harbor, ME, USA) and expanded and maintained in the animal facility of the Center of Postgraduate Medical Education (Warsaw, Poland). Mice were kept under pathogen-free conditions and fed with standard sterilized diet and sterile drinking water ad libitum. The animal study was approved by Local Ethics Committee No. 4 in Warsaw, Poland.

Four- to five-week-old female mice received intraperitoneal (i.p.) injection of busulfan (Sigma-Aldrich) for two consecutive days before cell transplantation. Mice were injected with the busulfan dose of $25 \mathrm{mg} / \mathrm{kg}$ in $100 \mu \mathrm{l}$ of $30 \%$ DMSO in saline. Twenty-four hours after the last myeloablative injection, mice received intravenous infusion (via a tail vein) of $10^{5}$ purified $\mathrm{UCB} \mathrm{CD}^{+} 4^{+}$cells in $100 \mu \mathrm{l}$ of $0.9 \% \mathrm{NaCl}$. After the transplantation, mice were observed and bred for further experiments.

\section{Model of LPS endotoxemia}

Because of the variability in the level of human cell chimerism after the transplantation of $\mathrm{CD} 34^{+}$cells, the injected mice were pair-matched before the proper experiments. Seven weeks after transplantation, $50 \mu \mathrm{l}$ of the peripheral blood was collected from the tail vein and placed in the EDTA-containing tubes. Next, the total cell count was evaluated (by using Bürker chamber and Türk's solution) and the percentage of human $\mathrm{CD} 45^{+}$ cells was analyzed by flow cytometry after staining with anti-CD45 PE antibody (BD Biosciences). Animals with chimerism varying less that $\pm 2 \%$ were matched into pairs and subjected to experimental endotoxemia or CLP models. Eight weeks after the transplantation, the selected paired mice were subjected to endotoxemia, receiving an intravenous injection of $40 \mu \mathrm{g}$ of LPS from E. coli O55:B5 (Sigma-Aldrich) in $100 \mu \mathrm{l}$ of $0.9 \%$ saline or $100 \mu \mathrm{l}$ of saline as control.

\section{Model of CLP sepsis}

A CLP model of sepsis of moderate severity was also performed 8 weeks after transplantation in accordance with the original protocol developed by Chaudry's lab [20] with additional modifications [21]. In brief, mice were anesthetized with i.p. injection of sodium pentobarbital (Sigma-Aldrich) with a dose of $30 \mathrm{mg} / \mathrm{kg}$. A midline incision was made, and after externalization, the cecum was ligated $(1 \mathrm{~cm}$ from the apex) and punctured twice (through-through) with a 22-G needle. Next, a small amount of fecal mass from the punctured cecum was gently squeezed out to ensure patency of punctures, cecum was relocated, and 4/0 sutures were used to close the peritoneum and skin. Sham-operated mice underwent only incision and cecum exteriorization.

Twenty-four hours after induction of endotoxemia or CLP, mice were anesthetized with sodium pentobarbital (200 $\mathrm{mg} / \mathrm{kg}$ ), bled from the retro-orbital plexus into EDTA, and terminated. The BM from each femur was flushed out with $0.5 \mathrm{ml}$ of PBS. From some control mice, splenocytes were isolated by mashing the spleen with a needle. Blood and BM cells were counted by using Bürker chamber and Türk's solution.

\section{Primary human bone marrow $\mathrm{CD} 34^{+}$cells in vitro stimulation}

Human BM was collected during the elective hip osteotomy from patients without severe comorbidities. Informed consent was obtained from all patients, and the study was approved by the local ethics board of the Center of Postgraduate Medical Education (Warsaw, Poland). After red blood cell lysis, CD34 ${ }^{+}$cells were isolated with an EasySep 
CD34 kit as described above. Freshly isolated BM CD34 $4^{+}$ cells $\left(4 \times 10^{5}\right)$ were stained with CellTrace Violet dye (Life Technologies, Carlsbad, CA, USA) in accordance with the protocol of the manufacturer. Next, cells were resuspended in StemSpam medium (Stemcell Technologies) with $10 \%$ FBS, split, and cultured in 96-well plate with $1 \mu \mathrm{g} / \mathrm{ml}$ of LPS (E. coli O55:B5, Sigma-Aldrich) or control medium. Cells were cultured in a humidified incubator with low oxygen concentration: $1 \% \mathrm{O}_{2}, 5 \% \mathrm{CO}_{2}$ and $94 \% \mathrm{~N}_{2}$ for 9 days. To trace their proliferation history, cells were stained after 9 days with anti-CD34 FITC, antiCD38 PE.Cy7, and 7-AAD (BD Biosciences) and analyzed by flow cytometry.

\section{Flow cytometry analysis}

Immunophenotyping analysis of human cells was performed by using a flow cytometry technique. Briefly, $70 \mu \mathrm{l}$ of cell suspension was incubated for $5 \mathrm{~min}$ with $5 \mu \mathrm{l}$ of inactivated mice serum to block murine Fc receptors. Then, $5 \mu \mathrm{l}$ of monoclonal antibodies-CD34APC, CD34 PE.Cy7, CD38-PE.Cy7, TLR4-PE, CXCR4biotin + streptavidin APC.Cy7, Lin-FITC (CD19, CD2, CD3, CD14, CD66b, CD24, CD16, CD56, and CD235a), CD45-AmCyan, CD19-PE, CD3-FITC, CD33-PerCP, CD14-PE, CD235a-APC, and CXCR4-biotin (BD Biosciences), TLR4-PE (R\&D Systems, Minneapolis, MN, USA), and G-CSFR-APC (BioLegend, San Diego, CA, USA)-was added and incubated for $30 \mathrm{~min}$ at room temperature. After staining, red blood cells were lysed with BD Pharm Lyse solution (BD Biosciences) for 10 min, washed with PBS with $2 \%$ Newborn Calf Serum (NCS), and resuspended in $0.5 \%$ paraformaldehyde in PBS. For Ki-67 and Notch Intracellular Domain (NICD) intracellular staining, fixed cells were washed with PBS and permeabilized by $0.25 \%$ Triton X-100 in PBS. Next, $5 \mu \mathrm{l}$ of anti-Ki-67 PE antibody, isotype control (BD Biosciences), or anti-NICD (Cell Signaling Technology, Danvers, MA, USA) was added for $30 \mathrm{~min}$, and after PBS wash, cells were resuspended again in paraformaldehyde. Prior to use, the anti-NICD antibody was labeled by using a Zenon AlexFluor 647 labeling kit (Life Technologies). For CXCR4 staining, before fixation, the cells were incubated with Streptavidin-PE (BD Biosciences) for $30 \mathrm{~min}$ and washed. Apoptosis of human HSPCs was analyzed with Annexin V-PE (BD Biosciences) in accordance with the protocol of the manufacturer. To analyze the expression of Jagged-1 on murine stromal cells, femurs of NSG mice were dissected, crushed, and incubated in $0.1 \%$ collagenase II in PBS (Sigma-Aldrich) in $37{ }^{\circ} \mathrm{C}$ for $90 \mathrm{~min}$. Then the cell suspension was filtered via $70-\mu \mathrm{m}$ mesh, washed in PBS, and stained with anti-mouse antibodies: anti-Jagged-1 PE antibody (eBioscience, San Diego, CA, USA), anti-CD31 and anti-rat IgG BV421 (BioLegend), and anti-CD45 FITC (BD Biosciences). At least 400 (450-700) $\mathrm{CD} 45^{-} \mathrm{CD} 31^{+}$ cells were collected in a flow cytometer. Phosphorylation of STAT3 in human HSPCs was assessed by intracellular staining with anti-pSTAT3-PE (pY705) antibody after permabilization with Phosphoflow Perm Buffer II (all from BD Biosciences) in accordance with the instructions of the manufacturer. Samples were analyzed by using a FACS Canto II cytometer (BD Biosciences) with Diva software. Approximately 100,000 cells were collected for analysis. Data analysis was performed with FlowJo software (Tree Star, Inc., now part of FlowJo LLC, Ashland, OR, USA). ModFit software was applied to analyze proliferation of in vitro cultured $\mathrm{BM} \mathrm{CD} 4^{+}$cells. All used anti-human antibodies were tested for cross-reactivity with cells of non-transplanted mice, and no staining was present.

\section{In vivo inhibition of Notch signaling}

To inhibit the Notch signaling pathway, mice were treated with DAPT, a $\gamma$-secretase inhibitor. Two hours before CLP surgery, hu-mice received i.p. injection of DAPT (Sigma-Aldrich) $(60 \mathrm{mg} / \mathrm{kg})$ dissolved in $50 \mu \mathrm{l}$ of DMSO. The effects of Notch inhibition on human HSPCs were evaluated $24 \mathrm{~h}$ after CLP.

\section{Colony-forming unit assay}

After erythrocyte lysis with Red Blood Cell Lysing Buffer (Sigma-Aldrich), BM cells $\left(5 \times 10^{5}\right)$ from humanized mice were used for the hematopoietic colony-forming unit (CFU) assay. The human methylcellulose-based medium (R\&D Systems) contains $25 \% \mathrm{FBS}, 2 \%$ bovine serum albumin, $2 \mathrm{mM}$ L-glutamine, and $5 \times 10^{-5} \mathrm{M}$ of mercaptoethanol and is supplemented with rh-SCF $(50 \mathrm{ng} / \mathrm{ml})$, rh-GM-CSF (10 ng/ml), rh-IL-3 (10 ng/ml), and rh-Epo (3 IU/ml). Cells were plated in duplicate in $35-\mathrm{mm}$ Petri dishes. After 20 days of culture in a humidified incubator in $37{ }^{\circ} \mathrm{C}$ and $5 \% \mathrm{CO}_{2}$, the colonies were counted under an inverted microscope. CFU-GM (granulocyte macrophage), CFU-G (granulocyte), CFU-M (macrophage), and CFU-E (erythroid)/burst-forming unit-erythroid (BFU-E) colonies were identified. The medium was tested for supporting growth of murine BM cells prior to experiments, and no colonies were formed by cells from nontransplanted mice.

\section{Statistical analysis}

Results are expressed as mean value \pm standard deviation. Absolute numbers of particular cell populations were calculated from the total cell count and frequency of given population. Statistical comparison between the matched control and experimental animals was performed with non-parametric Wilcoxon paired test. For multiple comparisons, the one-way analysis-of-variance test with Tukey's post test was used after testing the normal distribution of data sets with Kolmogorov-Smirnov test. A $P$ value of less than 0.05 was considered significant. 
Each group consisted of three to eight mice. GraphPad Prism 5 software (GraphPad Software, Inc., San Diego, CA, USA) was used for all statistical analyses.

\section{Results}

Development of the human multilineage reconstitution in NSG mice

To enable a robust engraftment of human cells in the NSG recipients, we performed a conditioning myeloablation with busulfan as reported by others [22]. The applied regimen was well tolerated by all animals. Xenotransplantation of $10^{5}$ purified UCB CD34 ${ }^{+}$cells after 8 weeks resulted in the BM engraftment by human cells at an average of $57.5 \pm 22 \%$. This percentage is higher than reported previously [22], but the increase can be attributed to the modified regimen of the busulfan treatment $(2 \times 25 \mathrm{mg} /$ $\mathrm{kg}$ ) that we used.
Among all human hematopoietic cells, we identified HSPCs as well as differentiated myeloid and lymphoid cells (Fig. 1). Although human erythrocytes were not detected in the peripheral blood, the BM contained cells from the erythroid lineage as determined by the expression of hu-glycophorin A (CD235a). In the peripheral blood, the human $\mathrm{CD} 45^{+}$leukocytes were present at frequencies of $1-29 \%$, mostly being $\mathrm{CD} 19^{+}$or $\mathrm{CD}_{3}{ }^{+}$ (data not shown). Within the splenocytes, hu-CD $45^{+}$ cells were present at the average of $17 \pm 9 \%$. Human hematopoietic cells residing in the murine BM expressed TLR4: the antigen was present on both differentiated (Lineage $^{+}$) and the Lineage ${ }^{-}$undifferentiated cells (Fig. 1j). Both CD $34^{+} \mathrm{CD}^{-} 8^{-} \mathrm{HSCs}$ and $\mathrm{CD} 34^{+} \mathrm{CD} 38^{+}$progenitors (Fig. 1h) expressed TLR4; the TLR4 surface density was higher on the latter cells (Fig. 1i).

In summary, a substantial difference in the frequency of particular leukocyte populations in hu-NSG mice

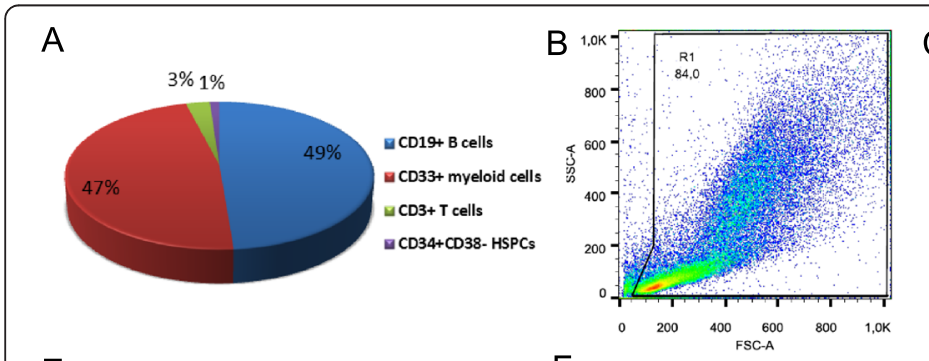

E
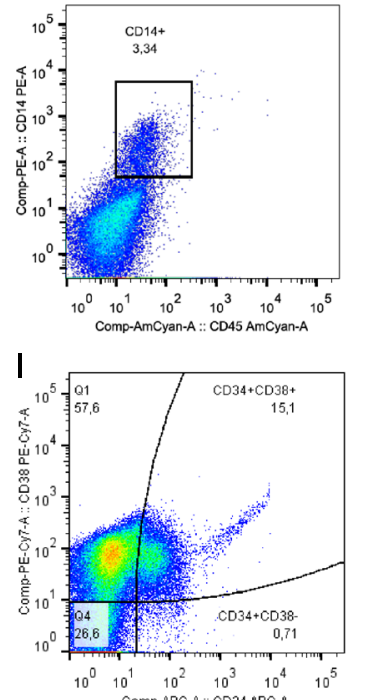

$\mathrm{F}$
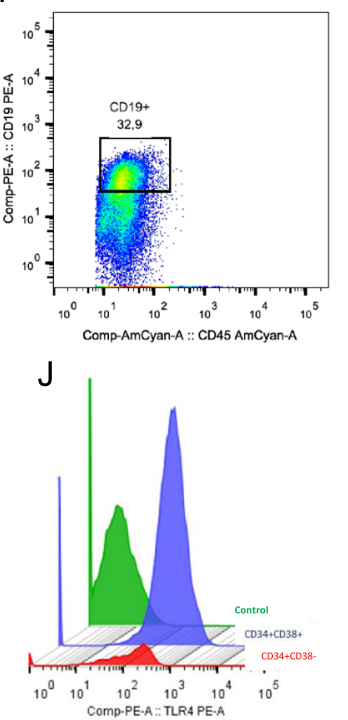

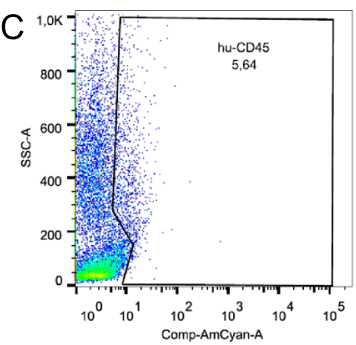

G
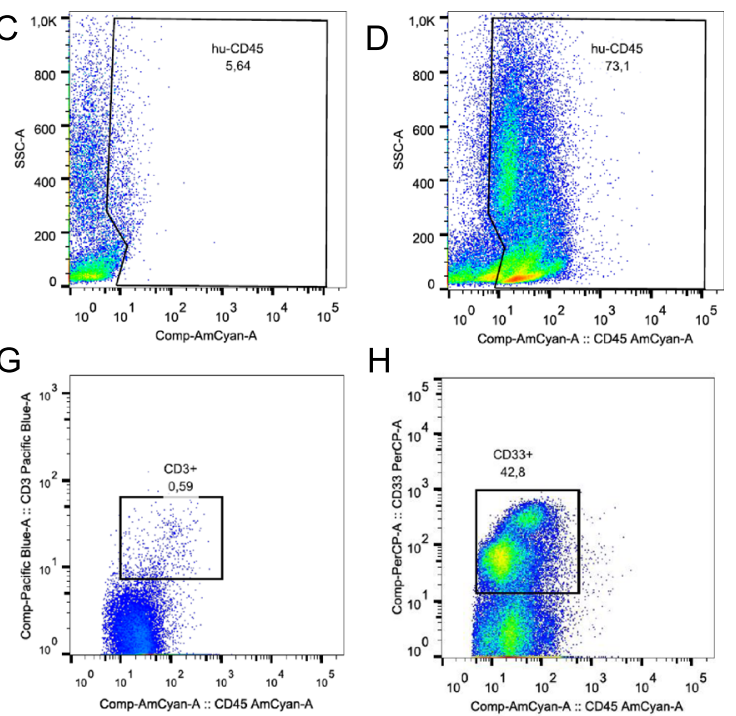

$\mathrm{H}$

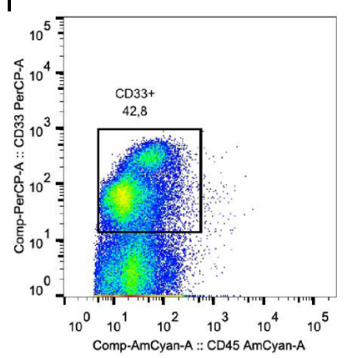

$\mathrm{K}$

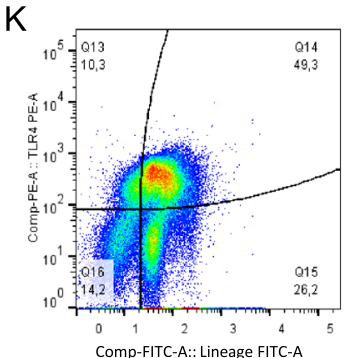

Fig. 1 Development of human hematopoietic cells in the bone marrow of NSG mice 8 weeks after transplantation of human CD34 ${ }^{+}$cells. Representative dot plots show flow cytometry analysis of bone marrow cells with specific anti-human monoclonal antibodies. a Diagram showing mean frequency of human leukocyte subsets in the bone marrow of humanized mice. $\mathbf{b}$ Staining of bone marrow from non-humanized NSG mouse with anti-human CD45. c Morphology of bone marrow cells from hu-NSG. $\mathbf{d}$ Expression of pan-hematopoietic CD45 antigen in cells gated in R1. e Analysis of monocytes. f Analysis of B cells. $\mathbf{g}$ Analysis of T cells. $\mathbf{h}$ Analysis of myeloid cells. $\mathbf{i}$ Analysis of hematopoietic stem and progenitor cells (gated from R1). $\mathbf{j}$ Histogram comparing expression of TLR4 receptor on HSCS and progenitor cells (gated from i). $\mathbf{k}$ Expression of TLR4 is present on both undifferentiated Lineage ${ }^{-}$cells and mature Lineage ${ }^{+}$cells. The values on graphs present percentages of a given population from a maternal gate. HSC hematopoietic stem cell, hu-NSG humanized NOD.Cg-Prkdc/scidlL2ry, NSG NOD.Cg-Prkdc/scidlL2ry, TLR Toll-like receptor 
and humans exists. However, a high frequency of humyeloid cells, together with expression of hu-TLR4 receptor, makes those mice a suitable model for studying human-specific immune-inflammatory responses elicited by sepsis and endotoxemia.

\section{Endotoxemia and CLP modulated human hematopoietic} stem and progenitor cell populations in humanized mice All animals survived the administered dose of LPS, and the mortality in the CLP model reached $40 \%$ after $24 \mathrm{~h}$. As specified in the Methods section, mice were matched for experimental pairs on the basis of the frequency of human chimerism in the peripheral blood of mice analyzed 7 days before experiments. The pairing was efficient as the correlation coefficients $(r)$ between groups were $0.899(P=0.016$ in CLP experiments) and $0.677(P=0.022$ in LPS experiments).

After $24 \mathrm{~h}$, cellularity of the BM was markedly reduced after both endotoxemia $\left(3.7 \times 10^{6} \pm 1.4 \times 10^{6} / \mathrm{ml}\right.$ versus $\left.5.9 \times 10^{6} \pm 2.7 \times 10^{6} / \mathrm{ml}, P<0.05\right)$ and CLP $\left(3.6 \times 10^{6} \pm\right.$ $1.6 \times 10^{6}$ versus $6.3 \times 10^{6} \pm 3.7 \times 10^{6} / \mathrm{ml}, P>0.05$, Fig. $2 \mathrm{a}$, e). CLP-induced sepsis increased both the frequency ( $3.8 \pm$ $1.1 \%$ versus $0.65 \pm 0.32 \%, P<0.01$, Fig. 2f) and total cell count $\left(1.5 \times 105 \pm 0.8 \times 10^{5} / \mathrm{ml}\right.$ versus $0.3 \times 10^{5} \pm$ $0.2 \times 10^{5} / \mathrm{ml}, P<0.05$, Fig. 2f) of the early CD $34^{+} \mathrm{CD} 38^{-}$ HSPCs. However, the frequency of the more committed $\mathrm{CD}_{3}{ }^{+} \mathrm{CD}_{3}{ }^{+}$progenitors did not change significantly after CLP. After LPS injection, the number of CD34 ${ }^{+}$ $\mathrm{CD} 38^{-}$cells was increased, but the difference did not reach significance $(13 \pm 9.6 \%$ versus $5.4 \pm 2.9 \%, P>0.05$, Fig. 2b).

We also analyzed the proliferative status of the human HSPCs by staining Ki-67, a protein indicative of cells that are in the active phases of the cell cycle. The frequency of $\mathrm{Lin}^{-} \mathrm{CD} 34^{+} \mathrm{Ki}-67^{+}$HSPCs was significantly increased $24 \mathrm{~h}$ after induction of CLP $(2.08 \pm 0.68 \%$ versus $1.36 \pm 0.69 \%)$ but not after endotoxemic challenge (Fig. 2d, h). Both models induced expansion of early HSPCs in the BM, and

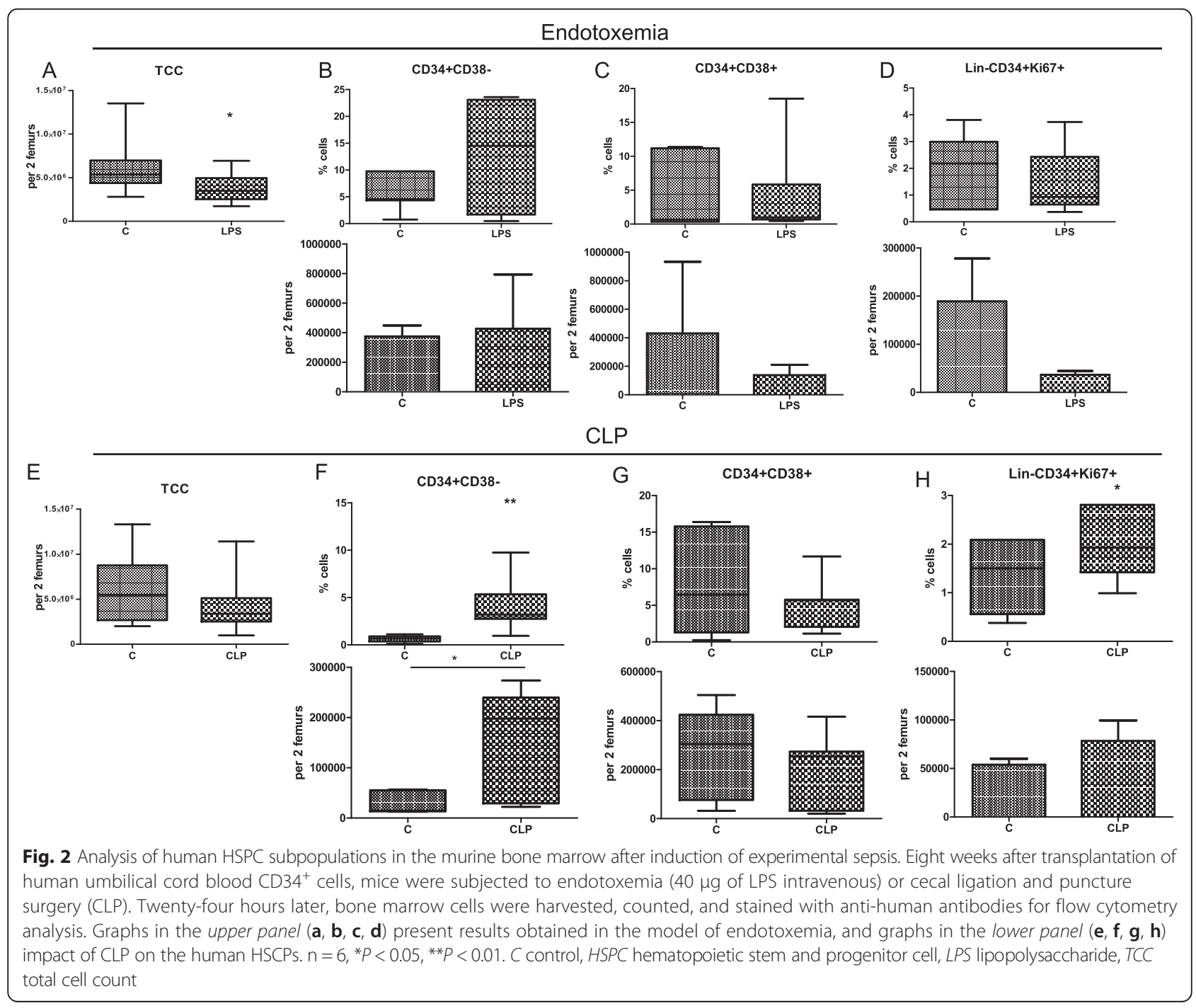


the effect on the progenitor cells was insignificant. Finally, we assessed the more differentiated population of human cells; CLP-induced sepsis led to a 3.5-fold reduction of $\mathrm{CD}^{+}{ }^{+}$myeloid cells $(16.98 \%$ versus $4.89 \%, P<0.05)$, but the impact of sepsis on $\mathrm{CD} 20^{+} \mathrm{B}$ cells was insignificant.

\section{Endotoxemia and CLP reduced hematopoietic colony forming by human cells}

In the next step, we aimed to test the impact of endotoxemia and CLP on the functionality and number of huhematopoietic progenitors. To do this, we used the CFU assay with medium supplemented with recombinant human cytokines which do not support growth of murine cells. The differences in baseline production of CFUs from control mice in both models (Fig. 3) are a result of different human chimerism after transplantation, but each time control mice were paired with experimental mice on the basis of human cell chimerism. Human hematopoietic cells isolated from the BM of mice injected with LPS formed four-fold fewer colonies compared with control mice. A similar effect occurred in cells from CLP mice: a two-fold reduction was observed.

Specifically, endotoxemia significantly reduced the growth of CFU-G ( $2 \pm 2$ versus $26 \pm 20)$ and CFU-M (0.85 \pm 0.5 versus $14.5 \pm 9$ ). In CLP mice, this phenomenon was less dramatic in CFU-G $(25.5 \pm 17$ versus $35 \pm 14$ in control, $P<0.05)$, but the number of CFU-M was not affected $(21.5 \pm 15$ versus $25.9 \pm 13.9)$. In contrast, CLP reduced the CFU-GM formation by $39 \%$ ( $35 \pm 23$ versus $57 \pm 23$ in control, $P<0.05$ ), but endotoxemia did not influence that type of progeny. Both models induced a markedly decreased the growth of BFU-E: in endotoxemia by 37 -fold and in CLP by three-fold (Fig. 3). In summary, both models significantly diminished the functional activity of human HPCs from the humanized BM.

\section{Endotoxemia and CLP upregulated expression of TLR4 and CXCR4 on human HSPCs}

Given that the HSPC fate can be influenced via TLR receptors and that TLR4-mediated recognition of pathogens is considered a key signaling axis in Gram-negative and polymicrobial infections, we then analyzed modulation of the TLR4 expression. In CLP sepsis, there was a two-fold increase in the frequency of the TLR4-positive CD34 $^{+} \mathrm{CD}^{-}{ }^{-}$cells $(55 \pm 13.4 \%$ versus $26.1 \pm 13.4 \%$; Fig. 4a-d). Moreover, the geometric mean fluorescence of anti-TLR4 staining increased by $43 \%$ (Fig. $4 \mathrm{~b}, \mathrm{~d}, \mathrm{~g}$ ). Similar results were obtained in endotoxemia: the TLR4positive $\mathrm{CD}^{+} 4^{+} \mathrm{CD} 38^{-}$cells and the fluorescence intensity increased by $63 \%$ and $46 \%$, respectively (Fig. 4a, c).

Because the retention and mobilization of HSPCs can contribute to changes in their BM quantity, we also attempted to evaluate the impact of sepsis on the expression of CXCR4, the key receptor involved in the
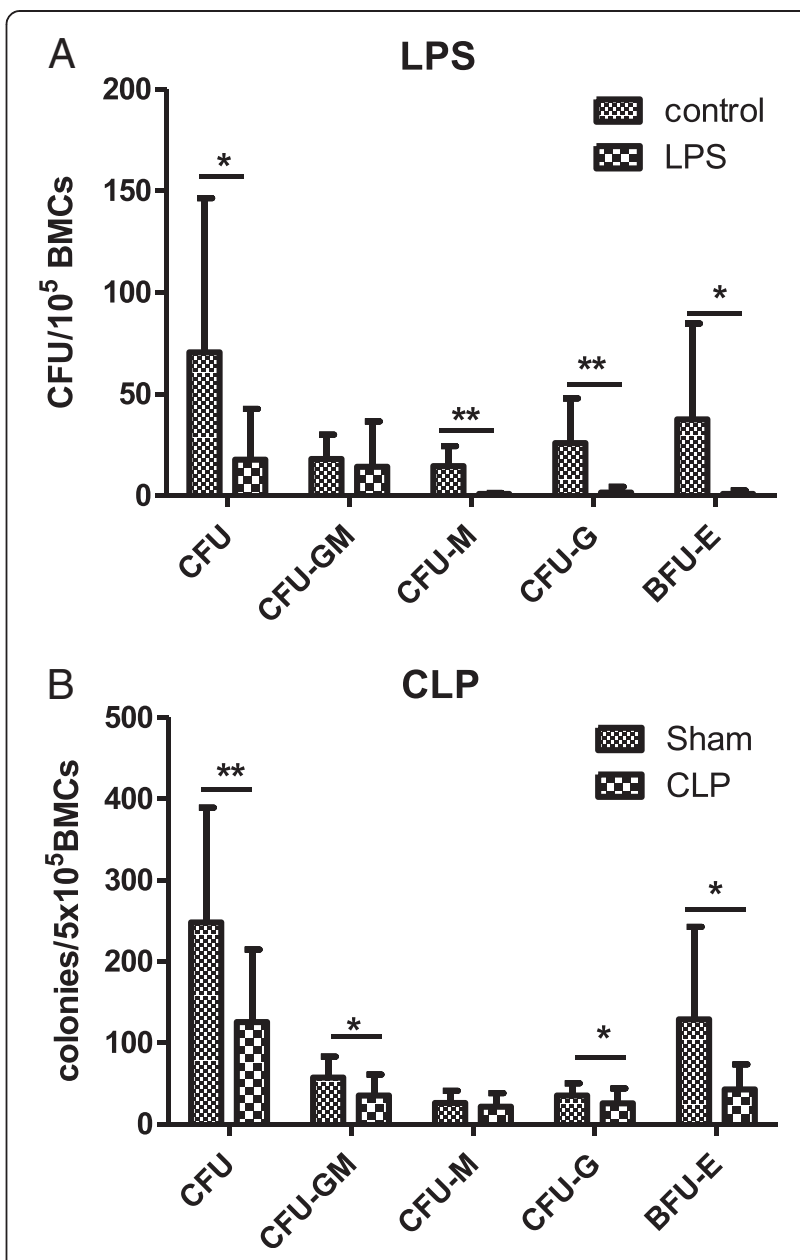

Fig. 3 Analysis of the growth of human hematopoietic colonies from bone marrow cells isolated from humanized mice $24 \mathrm{~h}$ after induction of experimental sepsis. Twenty-four hours after induction of experimental sepsis, bone marrow cells $\left(5 \times 10^{5}\right)$ from hu-NSG were seeded on methylocellulose medium supplemented with human growth factors. After 20 days of culture, the colonies formed by human progenitor cells were counted. a Results from the model of endotoxemia. $\mathbf{b}$ Results from the CLP-induced sepsis model. $n=6$, ${ }^{*} P<0.05$, ${ }^{*} P<0.01$. BMC bone marrow cell, CLP cecal ligation and puncture surgery, hu-NSG humanized NOD.Cg-Prkdc/scidIL2ry

maintenance of HSCs in the BM. CLP increased the density of CXCR4 on CD34 ${ }^{+}$CD $38^{-}$cells (Fig. 4e, h), whereas LPS had no effect on CXCR4 (Fig. 4f).

LPS stimulated proliferation and differentiation of primary human $\mathrm{BM} \mathrm{CD} 34^{+}$cells in vitro

The modulation of hu-HSCs in in vivo models is the sum of complex signaling stimuli triggered by sepsis. Thus, we investigated how LPS-induced TLR4 stimulation influences proliferation of purified HSPCs. After 9 days of culture, the presence of LPS reduced the frequency of $\mathrm{CD}^{+} 4^{+} \mathrm{CD} 38^{-}$HSCs by $44 \%$ compared with control (Fig. 5a). As the cells were stained with a fluorescent dye (CellTrace Violet), we were able to trace the 


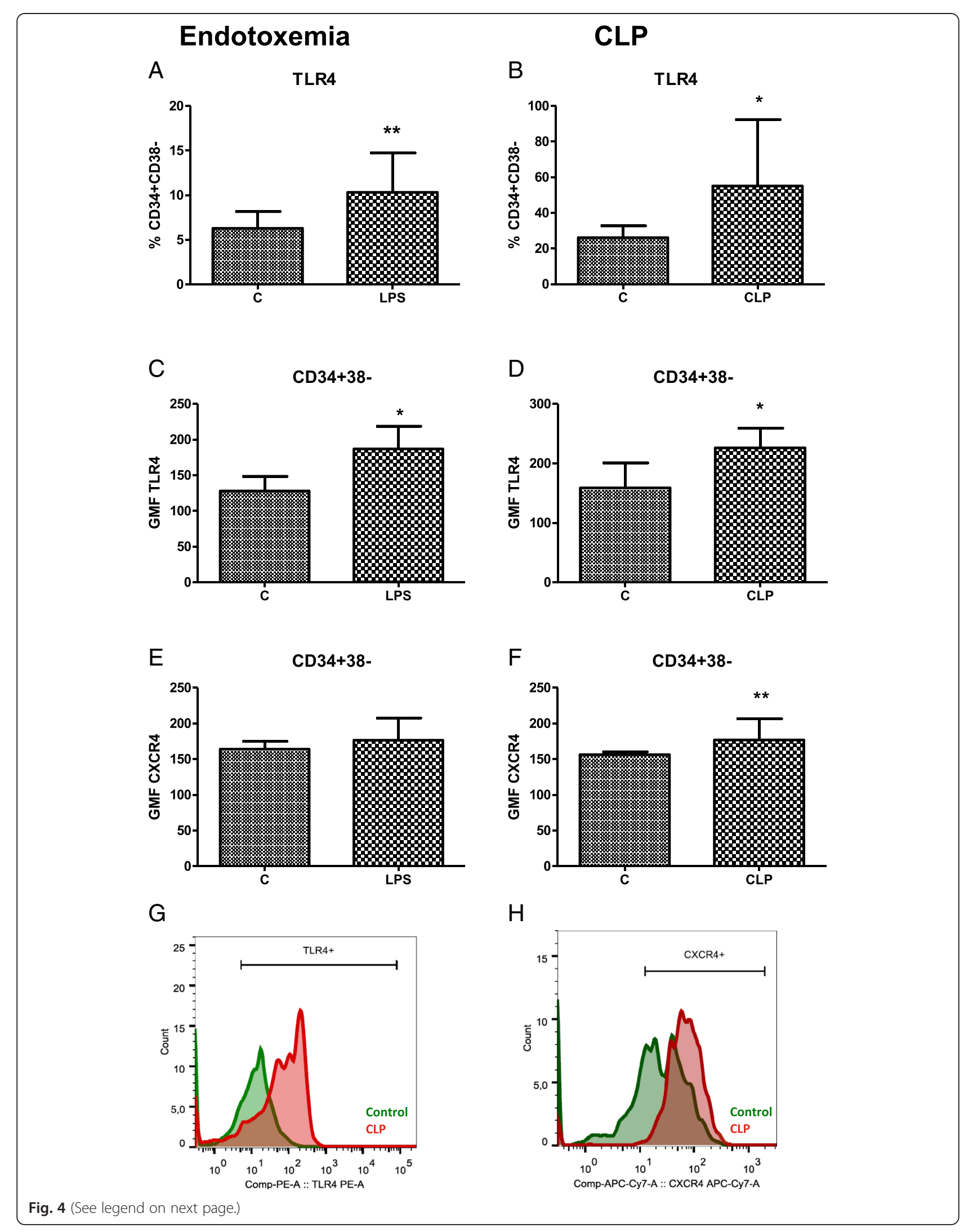


(See figure on previous page.)

Fig. 4 Modulation of the expression of TLR4 and CXCR4 receptors on human HSCs. Changes of TLR4 (a, c) and CXCR4 (e) expression on CD34 ${ }^{+}$CD38- cells $24 \mathrm{~h}$ after single LPS injection. Impact of CLP model on the modulation of TLR4 receptor expression (b, $\left.\mathbf{d}\right)$ and CXCR4 expression (f). Representative histograms of TLR4 (g) and CXCR4 (h) expression on CD34 $4^{+}$CD38- HSCs from control and CLP mice are presented. $\mathrm{n}=6,{ }^{*} P<0.05,{ }^{*} P<0.01$. CLP cecum ligation and puncture, GMF geometric mean fluorescence, HSC hematopoietic stem cell, LPS

lipopolysaccharide, TLR Toll-like receptor

proliferation history of each cell. When cultured in the medium alone, $\mathrm{CD} 34^{+} \mathrm{CD} 38^{+}$cells displayed higher proliferative activity (defined by proliferative index [23]) in comparison with CD34 ${ }^{+} \mathrm{CD}^{-} 8^{-}$cells $(14.3 \pm 5.4$ versus $7 \pm 2.1, P<0.05$ ) (Fig. 5b). The addition of LPS did not influence the proliferative index of $\mathrm{CD} 34^{+} \mathrm{CD} 38^{-} \mathrm{HSCs}$, but the index strongly increased in $\mathrm{CD} 34^{+} \mathrm{CD} 38^{+}$cells $(P<0.001)$ (Fig. 5 c). We also calculated frequency of the daughter cells in the first, second, and third generations. LPS did not change the frequency of $\mathrm{CD} 34^{+} \mathrm{CD} 38^{-}$cells within the sum of fewer than four generations, but it significantly decreased frequency of the $\mathrm{CD} 34^{+} \mathrm{CD} 38^{+}$cells in fewer than four generations (by nine-fold) (Fig. 5d, e). These observations suggest that LPS accelerated the proliferation of the more differentiated $\mathrm{CD} 34^{+} \mathrm{CD} 38^{+}$ cell population.
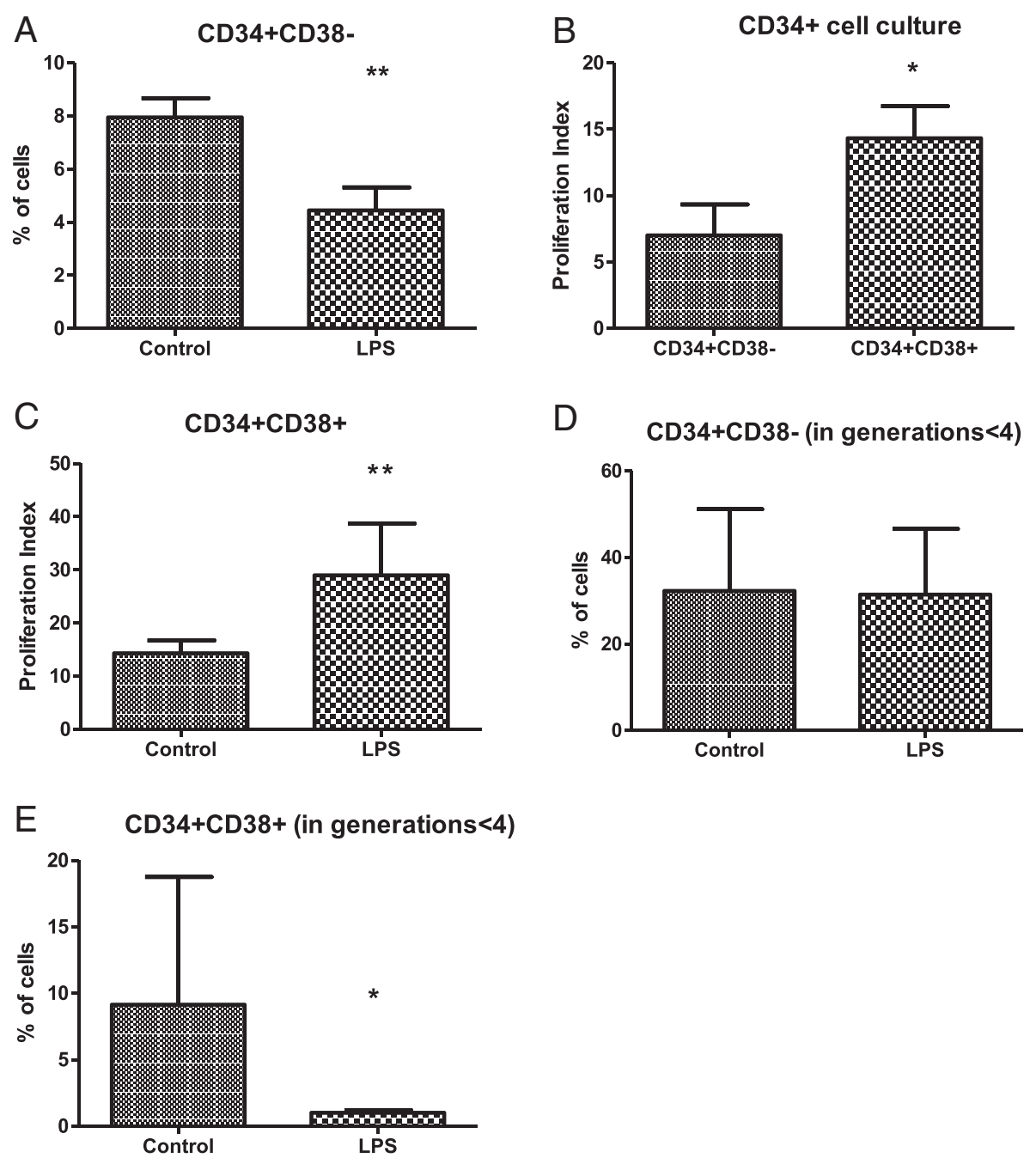

Fig. 5 Impact of LPS on the differentiation and proliferation of purified CD34 $4^{+}$human BM cells in vitro. a Effect of LPS on the frequency of the $\mathrm{CD} 34^{+} \mathrm{CD} 38^{-}$subpopulation after 9 days of culture. $\mathbf{b}$ Effect of LPS on the proliferative index of $\mathrm{CD} 34^{+} \mathrm{CD} 38^{+}$subpopulation. $\mathbf{c}$ Proliferation of $\mathrm{CD}_{4}{ }^{+} \mathrm{CD} 38^{+}$cells in the presence of LPS. Impact of LPS on the frequency of CD34 $4^{+} \mathrm{CD} 38^{-}$cells (d) and CD34 $4^{+} \mathrm{CD} 38^{+}$cells (e) within first, second, and third generations of daughter cells (fewer than four generations). All results obtained after 9 days of culture in atmosphere of $1 \% \mathrm{O}_{2} . \mathrm{n}=6$, ${ }^{*} P<0.05,{ }^{* *} P<0.001$. BM bone marrow, LPS lipopolysaccharide 
Endotoxemia modulated the Jagged-1 expression in the bone marrow

The Notch signaling pathway is co-responsible for maintaining the quiescent HSCs. Therefore, in the last step, we evaluated the expression of Notch-1 ligand Jagged-1 in the murine marrow stromal cells. Twelve hours after the LPS injection, the expression of Jagged-1 was upregulated on the $\mathrm{CD} 45^{-}$fraction and $\mathrm{CD} 45^{-} \mathrm{CD} 31^{+}$endothelial cells by $35 \%(P<0.05)$ (Fig. 6).

\section{Sepsis activated the Notch signaling pathway that was responsible for the expansion of human HSCs}

To assess the contribution of Notch signaling pathway in the expansion of human HSCs during CLP sepsis, we treated hu-mice with DAPT prior to the CLP surgery. DAPT is a $\gamma$-secretase inhibitor known to efficiently block the cleavage of the NICD which subsequently activates transcription of downstream target genes [24]. The activation of Notch-1 signaling was detected by staining of its cytoplasmic subunit, NICD.

CLP led to a significant increase in the fluorescence of NICD in CD34 ${ }^{+} \mathrm{CD}^{-}$cells which was abrogated by DAPT pretreatment (Fig. 7a). This effect was similar in $\mathrm{CD} 4^{+} \mathrm{CD}^{+} 8^{+}$cells, although the differences did not reach significance (Fig. 7a). The Notch blockade resulted in a seven-fold reduction of the expansion of primitive $\mathrm{CD}^{+}{ }^{+} \mathrm{CD}^{-} 8^{-}$(Fig. 7b, c) but had no effect on the more mature $\mathrm{CD} 4^{+} \mathrm{CD} 38^{+}$population (Fig. $7 \mathrm{~d}$, e). In addition, the percentage of actively proliferating CD34 ${ }^{+} \mathrm{Lin}^{-} \mathrm{HSCs}$ decreased in the presence of DAPT from $58 \%$ to $37 \%$ $(P<0.001$, Fig. 7f $)$.

To analyze the mechanisms controlling the HSC number, the rate of apoptosis was also measured. CLP alone increased the rate of Annexin V-positive CD34 ${ }^{+} \mathrm{CD}^{-}$ HSCs by five-fold $(P>0.05)$, and DAPT treatment further augmented this rate by 15 -fold compared with sham animals $(P<0.001$, Fig. $7 \mathrm{~g})$.

As the response to bacterial infections often evokes the G-CSF-driven process of emergency myelopoiesis [4], we analyzed the impact of sepsis on the expression of G-CSF receptors on human HSPCs. CLP increased the expression of G-CSFR on the surface of CD $34^{+}$CD $38^{-}$cells $(P<0.05)$ and $\mathrm{CD} 34^{+} \mathrm{CD} 38^{+}$cells $(P>0.05)$ and this effect was independent of the Notch activity (Fig. $7 \mathrm{~h}$ ).

The G-CSFR-induced stimulation of HPCs during emergency hematopoiesis is mediated by phosphorylation of STAT3 protein which activates translation of downstream genes [4]. Sepsis increased the percentages of both $\mathrm{CD}_{3} 4^{+} \mathrm{CD} 38^{-}$and $\mathrm{CD}^{+} 4^{+} \mathrm{CD}^{+} 8^{+}$with phosphorylated STAT3 and this effect was diminished by DAPT treatment, suggesting partial crosstalk between these two pathways (Fig. 7i). These results imply broad effects of Notch signaling in the proliferation and survival of HSCs during sepsis.

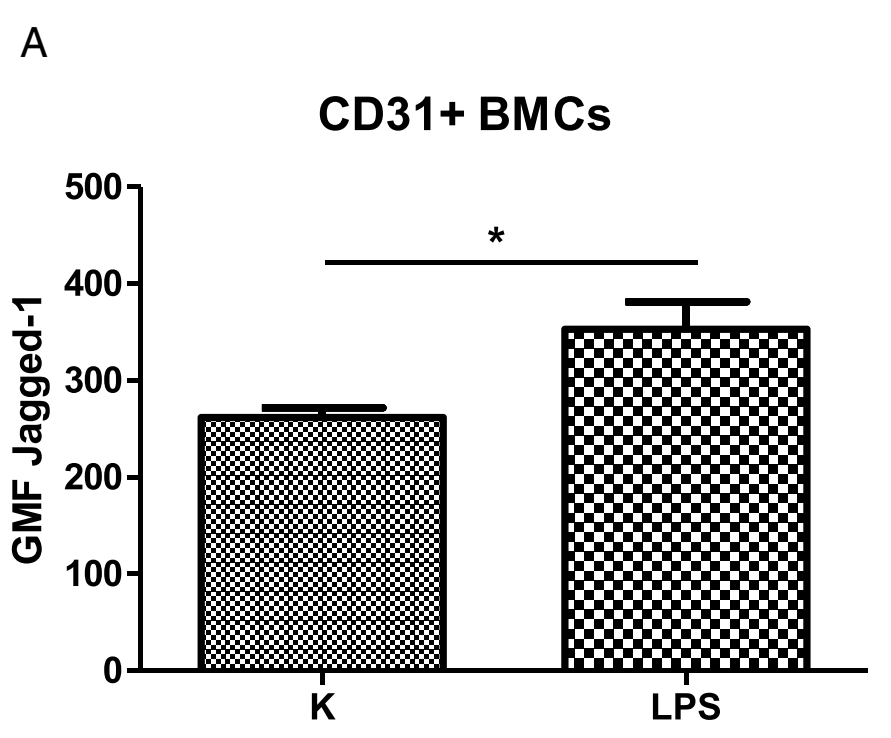

B

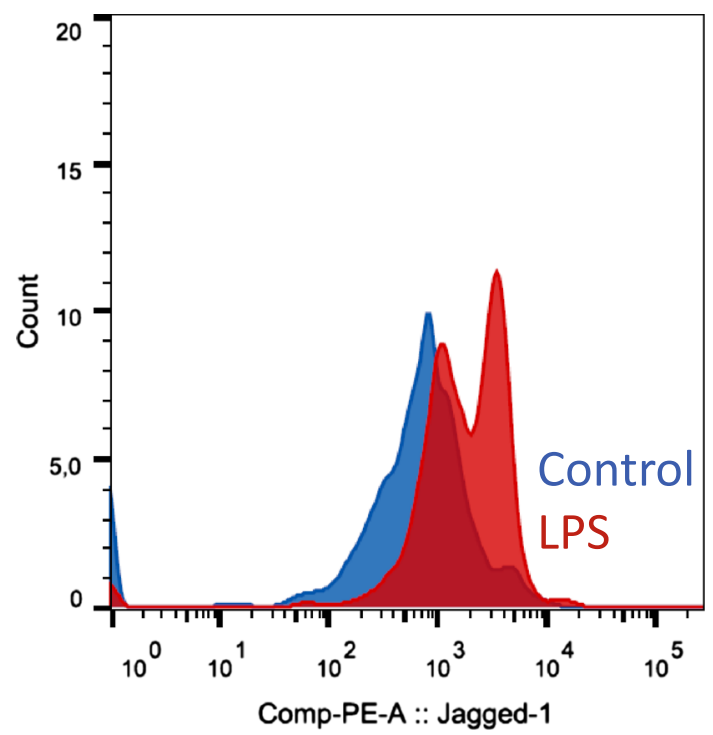

Fig. 6 Endotoxemia modulates expression of Jagged-1, a Notch-1 ligand on the bone marrow endothelial cells. Twelve hours after injection of LPS (40 $\mu \mathrm{g})$, murine femurs were crushed and digested with collagenase II, and then cells were stained with anti-mouse CD45, anti-mouse CD31, and anti-mouse Jagged- 1 antibodies. Expression of Jagged- 1 on murine $\mathrm{CD}_{4} 5^{-} \mathrm{CD} 31^{+}$endothelial cells was measured (a). $\mathbf{b}$ Representative histograms overlay of the expression of Jagged-1 after LPS injection and in control mice. $n=6,{ }^{*} P<0.05$. BMC bone marrow cell, GMF geometric mean fluorescence, LPS lipopolysaccharide 


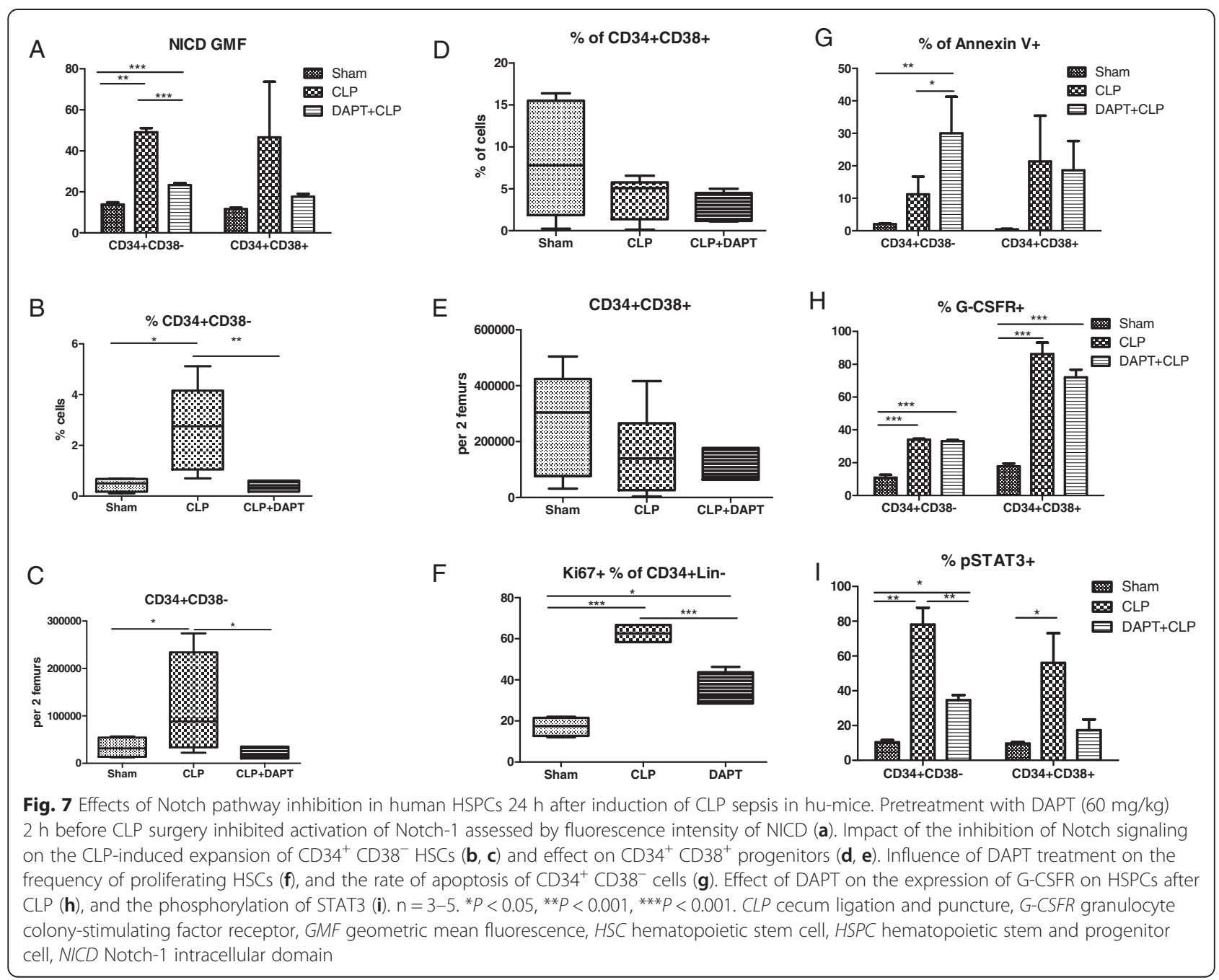

\section{Discussion}

This is the first study in which humanized mice were employed to study human HSPCs in the BM niche during experimental sepsis and endotoxemia. Both challenges in the chimeric mice provoked an active expansion of the primitive HSC populations with a concomitant decrease of the more committed progenitor pool. Moreover, we show that the changes observed in humanized mice were in contrast to those recorded after in vitro stimulation of HSPCs with LPS. Those findings underscore the importance of complexity of signal interactions in the $\mathrm{BM}$ and advance knowledge on the immune system reprogramming occurring during severe sepsis.

Similarly to other studies, the main population of the hu-BM cells consisted of B cells [25], whereas $\mathrm{T}$ cells constituted only $3 \%$ of the total BM cells. The recapitulation of human sepsis T-cell response in hu-mice has already been reported by the Hotchkiss group [16]. In their study, the CLP sepsis induced apoptosis of T cells and reduced the delayed-type hypersensitivity response [16]. Also, the myeloid cells in hu-mice were reported to display functional responses to cytokine stimulation (phosphorylation of STAT3 and STAT5 in response to G-CSF and STAT1, STAT3, and STAT5 after interferongamma treatment) [26].

Given that our mice developed a substantial percentage of $\mathrm{CD}_{3} 3^{+}$cells, they appear adequately competent to recapitulate such a response to sepsis. Human cells in the BM of our hu-mice express the TLR4 receptor, the major pattern-recognition receptor for LPS. TLR4 receptor was present on both differentiated cells Lineage $^{+}$) and HSPCs (Fig. 1h, i). Interestingly, 8 weeks after transplantation, hu-CD34 ${ }^{+}$cells constituted up to $13 \%$ of human $\mathrm{BM}$ cells, and the $\mathrm{CD} 34^{+} \mathrm{CD} 38^{-}$subpopulation was up to $5 \%$. These values are significantly higher than in the human BM, where those cell populations constitute, on average, $1.4 \%$ and $0.1 \%$, respectively [27]. This 
discrepancy can be due to either an increased capacity for self-renewal of the hu-HSPCs or their differentiation impairment in the murine $\mathrm{BM}$ niche. Altogether, our current model is suitable to study the impact of sepsis on human HSPCs.

To provide a wide coverage to the studied aim, we employed two different models, namely non-microbial endotoxemia and polymicrobial CLP. Because they differ in the kinetics of cytokine response [28] and in several other discrepancies existing between those two models [29], this enabled us to investigate potential differences in HSPC responses in two highly inflammatory milieus of different origin.

The uniform reduction in the BM cellularity after endotoxemia and sepsis can be explained by mobilization of myeloid cells to the peripheral blood and spleen [30]. However, the same number of BM cells from septic animals gave a lower number of hematopoietic colonies. This was observed in all types of colonies and in both models yet with a stronger suppression of CFU-M and CFU-G in endotoxemia. Interpretation of our findings is difficult as no similar studies have been performed in humanized mice to date; we can only compare our results with those obtained in immunocompetent (non-humanized) mice. Rodriguez et al. reported a similar inhibition of myeloid colony formation after injection of LPS from $P$. aeruginosa in C57/BL6 mice [12]. Also, a decrease of the erythroid colony formation was shown after induction of peritoneal sepsis in vivo as well as in vitro LPS stimulation of the BM cells [31]. In contrast, in different pre-clinical models, sepsis exerted a stimulatory effect on myeloid colonies $[31,32]$. The discrepancy of the myeloid progenitor activity between the abovementioned studies may be attributed to differences between the models themselves or their severity or both. In the future, it would be of interest to compare dynamic changes in the HSPC compartment of humanized mice subjected to sepsis of different severity.

Both endotoxemia and sepsis increased the frequency and the total cell count of $\mathrm{CD} 34^{+} \mathrm{CD} 38^{-}$cells in the BM of hu-NSG. Especially, the increase of the total number of those cells indicates that their expansion progressed in an active manner. Support for this claim comes from the upregulation in the expression of the $\mathrm{Ki}-67$ protein that is expressed in cycling cells [33]. Although CLP had a much stronger effect on the expression of Ki-67 in HSPCs, endotoxemia also increased frequency of proliferating cells. More differentiated $\mathrm{CD} 34^{+} \mathrm{CD} 38^{+}$cells were not significantly affected in our models, but a tendency to their reduction could be seen after LPS injection. CLP also reduced the pool of BM human $\mathrm{CD}^{+} 3^{+}$ myeloid cells similarly to wild-type models [30]. As it was shown that the mobilization of granulocytes from BM 'paves the way' for egress of progenitor cells [34], this mechanism can contribute to the decrease of the
BM progenitor pool in our model. Our results are consistent with data from a different type of endotoxemic insult: an infusion of $P$. aeruginosa LPS increased early HSCs but inhibited the colony formation [12].

The role of TLR4 signaling in HSPCs during infections has been controversial. On one hand, the expansion of HSCs from $T L R 4^{-/-}$mice to LPS was absent [11, 12]; on the other hand, those mice showed unchanged response to CLP and peritonitis [11, 35]. Nevertheless, recent reports prove the importance of TLR4 signaling in the steady-state granulopoiesis [36]. Interestingly, in our models, the expression of TLR4 was upregulated on both $\mathrm{CD}_{3} 4^{+} \mathrm{CD} 38^{-}$and $\mathrm{CD} 34^{+} \mathrm{CD} 38^{+}$cells and this is in contrast to modulation of those receptors on monocytes from patients with sepsis [37]. This collectively suggests an active participation of TLR4 in the response of HSPCs to sepsis. Moreover, in the CLP sepsis model, expression of CXCR4 on HSPCs was increased. A similar LPS-induced upregulation was observed in neutrophils, B cells, and murine HSPCs [38-40]. Such a receptor modulation may be responsible for enhanced retention of HSPCs in the BM or peripheral tissues [41].

To unravel the role of the BM microenvironment in the sepsis-induced HSC expansion, we traced the proliferation history of purified hu-CD34 $4^{+} \mathrm{BM}$ cells after culturing them in vitro with LPS. The results of the LPS experiment are in a stark contrast to the results obtained in hu-mice: LPS decreased the pool of $\mathrm{CD} 34^{+} \mathrm{CD} 38^{-}$ cells and strongly stimulated divisions of differentiated $\mathrm{CD}_{3} 4^{+} \mathrm{CD} 8^{+}$cells. We interpret this in vitro-versusin vivo discrepancy as proof for a strong influence of the BM microenvironment. To date, several important components of the BM niche have been recognized. As we maintained the cell culture in a hypoxic atmosphere that resembles conditions of the BM niche [42], we doubt that this factor had influenced the observed differences. Although we stimulated purified $\mathrm{CD} 34^{+}$cells with purified LPS, it was shown that CD34 ${ }^{+}$HSPCs are potent producers of cytokines and growth factors [43] and that the TLR4 signaling even increases production of cytokines by HSPCs (verified for murine cells [7]). Thus, cytokines produced in such an autocrine manner were likely present in our 9-day culture similarly to the BM milieu.

Altogether, we hypothesize that reshaping of the intercellular signaling in the BM niche may be responsible for the expansion and blocking of HSC differentiation in hu-mice. To identify a potential candidate responsible for this phenomenon, we evaluated the Jagged-1 (a ligand for Notch-1 receptor) expression after endotoxemia. Notch-1 signaling is a well-known, evolutionally conserved pathway that stimulates expansion and inhibits differentiation of early HSCs [44]. Indeed, LPS upregulated Jagged-1 expression on marrow 
stromal and endothelial cells. Then, we confirmed that CLP sepsis activated Notch-1 signaling in HSPCs, demonstrating that this pathway was responsible for the sepsis-induced proliferation and expansion of HSCs. Furthermore, this proliferation was dependent, at least partially, on the activation of STAT3. Concomitant upregulation of G-CSFR on HSCs during sepsis, a known inducer of STAT3 phosphorylation during emergency myelopoiesis, is probably responsible for the majority of STAT3 activation [45]. The crosstalk between Notch and STAT3 pathways was reported before [46], and our results suggest that such an interaction may be important during severe infections in HSCs. Interestingly, sepsis itself induced apoptosis (annexin $\mathrm{V}$ binding) in HSCs and to a greater extent in HPCs. Inhibition of Notch signaling by DAPT further increased the rate of apoptosis of HSCs but not HPCs. This finding underlines the exclusive importance of the Notch pathway in maintaining the expansion of more primitive HSCs. Therefore, it may be hypothesized that the activation of Notch in HSCs during sepsis serves as a mechanism that protects those cells from exhaustion during massive infections but may also reduce their maturation into more differentiated progenitors.

Our study has several drawbacks. Although hu-mice develop human immunocompetent cells, their composition does not ideally reflect the physiological human immune system. Moreover, the human cells are not fully differentiated. Thus, particular defense and regulatory mechanisms may be partially impaired or deregulated or both. Another limitation is the partial cross-reactivity of murine cytokines with human cells (e.g., M-CSF and interleukin-15 [47]).

\section{Conclusions}

In summary, we report that both endotoxemia and CLP induced proliferation and accumulation of human HSPCs in the BM niches but that the pool of hematopoietic progenitors strongly decreased. As this phenomenon was not recapitulated in the in vitro LPS stimulation of purified HSPCs, it highlights the importance of the BM microenvironment in modulation of HSPCs during sepsis. Furthermore, our findings suggest that increased Notch-1 signaling via Jagged-1 contributed to the abovementioned modulation. It is suggested that the impairment of HSC maturation in endotoxemia and sepsis may have significant implications in the development and progress of various immune disturbances in affected patients.

\section{Abbreviations}

BFU-E: Burst-forming unit-erythroid; BM: Bone marrow; CFU: Colony-forming unit; CFU-G: Colony-forming unit-granulocyte; CFU-GM: Colony-forming unit-granulocyte macrophage; CFU-M: Colony-forming unit-macrophage; CLP: Cecum ligation and puncture; DMSO: Dimethyl sulfoxide; FBS: Fetal bovine serum; G-CSF: granulocyte colony-stimulating factor; GCSFR: granulocyte colony-stimulating factor receptor; HPC: Hematopoietic progenitor cell; HSC: Hematopoietic stem cell; HSPC: Hematopoietic stem and progenitor cell; hu-NSG: Humanized NOD.Cg-Prkdc/scidlL2ry; i.p.: Intraperitoneal; LPS: Lipopolysaccharide; LT-HSC: long-term hematopoietic stem cell; NICD: Notch Intracellular Domain; NSG: NOD.Cg-Prkdc/scidIL2ry; PBS: Phosphate-buffered saline; TLR: Toll-like receptor; UCB: Umbilical cord blood.

\section{Competing interests}

The authors declare that they have no competing interests.

\section{Authors' contributions}

TS contributed to conception, experiments, data analysis, and manuscript writing. JK and $\mathrm{GH}$ contributed to conception, manuscript writing, and data interpretation. EM and ZP contributed to cord blood cell isolation. DW contributed to animal care and helped with experiments. JC contributed to BM cell collection. All authors read and approved the final manuscript.

\section{Acknowledgments}

This work was supported by European Union Structural Funds, 'Innovative methods of stem cells applications in medicine', Innovative Economy Operational Program, grant POIG 01.01.02-00-109/09. The authors gratefully acknowledge Marcin Osuchowski for his contribution to this manuscript. The work has been supported by European Union Structural Funds, "Innovative methods of stem cells applications in medicine".

\section{Author details}

1 Department of Flow Cytometry, The Center of Postgraduate Medical Education, Marymoncka 99/103, 01-813 Warsaw, Poland. ${ }^{2}$ Department of Anesthesiology and Intensive Care Medicine, The Center of Postgraduate Medical Education, Czerniakowska 231, 00-416 Warsaw, Poland. ${ }^{3}$ Department of Cellular Engineering, Maria Sklodowska-Curie Memorial Cancer Center and Institute of Oncology, W. Roentgena 5, 02-781 Warsaw, Poland. ${ }^{4}$ Department of Clinical Cytology, The Center of Postgraduate Medical Education, Marymocnka 99/103, 01-813 Warsaw, Poland. ${ }^{5}$ Department of Pediatric Orthopedics, The Center of Postgraduate Medical Education, Konarskiego 13, 05-400 Otwock, Poland.

Received: 22 March 2015 Revised: 23 March 2015

Accepted: 17 July 2015 Published online: 14 August 2015

\section{References}

1. Dombrovskiy VY, Martin AA, Sunderram J, Paz HL. Rapid increase in hospitalization and mortality rates for severe sepsis in the United States: a trend analysis from 1993 to 2003. Crit Care Med. 2007;35:1244-50.

2. Levy MM, Artigas A, Phillips GS, Rhodes A, Beale R, Osborn T, et al. Outcomes of the Surviving Sepsis Campaign in intensive care units in the USA and Europe: a prospective cohort study. Lancet Infect Dis. 2012;12:919-24.

3. Dellinger RP, Carlet JM, Masur H, Gerlach H, Calandra T, Cohen J, et al. Surviving Sepsis Campaign guidelines for management of severe sepsis and septic shock. Intensive Care Med. 2004;30:536-55.

4. Manz MG, Boettcher S. Emergency granulopoiesis. Nat Rev Immunol. 2014;14:302-14.

5. Nagai Y, Garrett KP, Ohta S, Bahrun U, Kouro T, Akira S, et al. Toll-like receptors on hematopoietic progenitor cells stimulate innate immune system replenishment. Immunity. 2006;24:801-12.

6. Boettcher S, Gerosa RC, Radpour R, Bauer J, Ampenberger F, Heikenwalder $\mathrm{M}$, et al. Endothelial cells translate pathogen signals into G-CSF-driven emergency granulopoiesis. Blood. 2014;124:1393-403.

7. Zhao JL, Ma C, O'Connell RM, Mehta A, DiLoreto R, Heath JR, et al. Conversion of danger signals into cytokine signals by hematopoietic stem and progenitor cells for regulation of stress-induced hematopoiesis. Cell Stem Cell. 2014;14:445-59.

8. Esplin BL, Shimazu T, Welner RS, Garrett KP, Nie L, Zhang Q, et al. Chronic exposure to a TLR ligand injures hematopoietic stem cells. J Immunol. 2011;186:5367-75.

9. Torgersen C, Moser P, Luckner G, Mayr V, Jochberger S, Hasibeder WR, et al. Macroscopic postmortem findings in 235 surgical intensive care patients with sepsis. Anesth Analg. 2009;108:1841-7.

10. Levy MM, Fink MP, Marshall JC, Abraham E, Angus D, Cook D, et al. 2001 SCCM/ESICM/ACCP/ATS/SIS International Sepsis Definitions Conference. Crit Care Med. 2003;31:1250-6. 
11. Scumpia PO, Kelly-Scumpia KM, Delano MJ, Weinstein JS, Cuenca AG, Al-Quran S, et al. Cutting edge: bacterial infection induces hematopoietic stem and progenitor cell expansion in the absence of TLR signaling. J Immunol. 2010;184:2247-51.

12. Rodriguez S, Chora A, Goumnerov B, Mumaw C, Goebel WS, Fernandez L, et al. Dysfunctional expansion of hematopoietic stem cells and block of myeloid differentiation in lethal sepsis. Blood. 2009;114:4064-76.

13. Zhang P, Nelson S, Bagby GJ, Siggins 2nd R, Shellito JE, Welsh DA. The lineage-c-Kit + Sca-1+ cell response to Escherichia coli bacteremia in Balb/c mice. Stem Cells. 2008;26:1778-86.

14. Osuchowski MF, Remick DG, Lederer JA, Lang CH, Aasen AO, Aibiki M, et al. Abandon the mouse research ship? Not just yet! Shock. 2014;41:463-75.

15. Shultz LD, Ishikawa F, Greiner DL. Humanized mice in translational biomedical research. Nat Rev Immunol. 2007;7:118-30.

16. Unsinger J, McDonough JS, Shultz LD, Ferguson TA, Hotchkiss RS. Sepsis-induced human lymphocyte apoptosis and cytokine production in "humanized" mice. J Leukoc Biol. 2009:86:219-27.

17. Lapidot T, Kollet O. The essential roles of the chemokine SDF-1 and its receptor CXCR4 in human stem cell homing and repopulation of transplanted immune-deficient NOD/SCID and NOD/SCID/B2m(null) mice. Leukemia. 2002;16:1992-2003.

18. Guezguez B, Campbell CJ, Boyd AL, Karanu F, Casado FL, Di Cresce C, et al. Regional localization within the bone marrow influences the functional capacity of human HSCs. Cell Stem Cell. 2013;13:175-89.

19. Rittirsch D, Hoesel LM, Ward PA. The disconnect between animal models of sepsis and human sepsis. J Leukoc Biol. 2007;81:137-43.

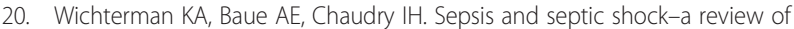
laboratory models and a proposal. J Surg Res. 1980;29:189-201.

21. Rittirsch D, Huber-Lang MS, Flierl MA, Ward PA. Immunodesign of experimental sepsis by cecal ligation and puncture. Nat Protoc. 2009;4:31-6.

22. Hayakawa J, Hsieh MM, Uchida N, Phang O, Tisdale JF. Busulfan produces efficient human cell engraftment in NOD/LtSz-Scid IL2Rgamma(null) mice. Stem Cells. 2009;27:175-82

23. Zolnierowicz J, Ambrozek-Latecka M, Kawiak J, Wasilewska D, Hoser G. Monitoring cell proliferation in vitro with different cellular fluorescent dyes. Folia Histochem Cytobiol. 2013;51:193-200.

24. Ilagan MX, Kopan R. SnapShot: notch signaling pathway. Cell. 2007;128:1246.

25. Matsumura T, Kametani Y, Ando K, Hirano Y, Katano I, Ito R, et al. Functional CD5+ B cells develop predominantly in the spleen of NOD/SCID/ gammac(null) (NOG) mice transplanted either with human umbilical cord blood, bone marrow, or mobilized peripheral blood CD34+ cells. Exp Hematol. 2003:31:789-97.

26. Tanaka S, Saito Y, Kunisawa J, Kurashima Y, Wake T, Suzuki N, et al. Development of mature and functional human myeloid subsets in hematopoietic stem cell-engrafted NOD/SCID/IL2rgammaKO mice. J Immunol. 2012;188:6145-55.

27. Hao QL, Shah AJ, Thiemann FT, Smogorzewska EM, Crooks GM. A functional comparison of CD34 + CD38- cells in cord blood and bone marrow. Blood. 1995;86:3745-53.

28. Remick DG, Newcomb DE, Bolgos GL, Call DR. Comparison of the mortality and inflammatory response of two models of sepsis: lipopolysaccharide vs. cecal ligation and puncture. Shock. 2000;13:110-6.

29. Fink MP. Animal models of sepsis. Virulence. 2014:5:143-53.

30. Delano MJ, Kelly-Scumpia KM, Thayer TC, Winfield RD, Scumpia PO, Cuenca $A G$, et al. Neutrophil mobilization from the bone marrow during polymicrobial sepsis is dependent on CXCL12 signaling. J Immunol. 2011;187:911-8.

31. Barthlen W, Zantl N, Pfeffer K, Heidecke CD, Holzmann B, Stadler J. Impact of experimental peritonitis on bone marrow cell function. Surgery. 1999;126:41-7.

32. Zhang P, Quinton LJ, Gamble L, Bagby GJ, Summer WR, Nelson S. The granulopoietic cytokine response and enhancement of granulopoiesis in mice during endotoxemia. Shock. 2005;23:344-52.

33. Soares A, Govender L, Hughes J, Mavakla W, de Kock M, Barnard C, et al. Novel application of Ki67 to quantify antigen-specific in vitro lymphoproliferation. J Immunol Methods. 2010;362:43-50.

34. Ratajczak MZ, Lee H, Wysoczynski M, Wan W, Marlicz W, Laughlin MJ, et al. Novel insight into stem cell mobilization-plasma sphingosine-1-phosphate is a major chemoattractant that directs the egress of hematopoietic stem progenitor cells from the bone marrow and its level in peripheral blood increases during mobilization due to activation of complement cascade/ membrane attack complex. Leukemia. 2010;24:976-85.
35. Cuenca AG, Cuenca AL, Gentile LF, Efron PA, Islam S, Moldawer LL, et al. Delayed emergency myelopoiesis following polymicrobial sepsis in neonates. Innate Immun. 2014;21:386.

36. Bugl S, Wirths S, Radsak MP, Schild H, Stein P, Andre MC, et al. Steady-state neutrophil homeostasis is dependent on TLR4/TRIF signaling. Blood. 2013;121:723-33.

37. Skinner NA, Maclsaac CM, Hamilton JA, Visvanathan K. Regulation of Toll-like receptor (TLR)2 and TLR4 on CD14dimCD16+ monocytes in response to sepsis-related antigens. Clin Exp Immunol. 2005;141:270-8.

38. Moon H, Lee JG, Shin SH, Kim TJ. LPS-induced migration of peritoneal B-1 cells is associated with upregulation of CXCR4 and increased migratory sensitivity to CXCL12. J Korean Med Sci. 2012;27:27-35.

39. Yamada M, Kubo H, Kobayashi S, Ishizawa K, He M, Suzuki T, et al. The increase in surface CXCR4 expression on lung extravascular neutrophils and its effects on neutrophils during endotoxin-induced lung injury. Cell Mol Immunol. 2011;8:305-14.

40. Trotta T, Di Gioia S, Piro D, Lepore S, Cantatore S, Porro C, et al. Effect of acute lung injury on VLA-4 and CXCR4 expression in resident and circulating hematopoietic stem/progenitor cells. Respiration. 2013;85:252-64.

41. Ohno N, Kajiume T, Sera Y, Sato T, Kobayashi M. Short-term culture of umbilical cord blood-derived CD34 cells enhances engraftment into NOD/SCID mice through increased CXCR4 expression. Stem Cells Dev. 2009;18:1221-6.

42. Eliasson P, Jonsson Jl. The hematopoietic stem cell niche: low in oxygen but a nice place to be. J Cell Physiol. 2010;222:17-22.

43. Majka M, Janowska-Wieczorek A, Ratajczak J, Ehrenman K, Pietrzkowski Z, Kowalska MA, et al. Numerous growth factors, cytokines, and chemokines are secreted by human CD34(+) cells, myeloblasts, erythroblasts, and megakaryoblasts and regulate normal hematopoiesis in an autocrine/ paracrine manner. Blood. 2001;97:3075-85.

44. Duncan AW, Rattis FM, DiMascio LN, Congdon KL, Pazianos G, Zhao C, et al. Integration of Notch and Wnt signaling in hematopoietic stem cell maintenance. Nat Immunol. 2005;6:314-22.

45. Zhang H, Nguyen-Jackson H, Panopoulos AD, Li HS, Murray PJ, Watowich SS. STAT3 controls myeloid progenitor growth during emergency granulopoiesis. Blood. 2010;116:2462-71.

46. Kamakura S, Oishi K, Yoshimatsu T, Nakafuku M, Masuyama N, Gotoh Y. Hes binding to STAT3 mediates crosstalk between Notch and JAK-STAT signalling. Nat Cell Biol. 2004;6:547-54.

47. Chen Q, Khoury M, Chen J. Expression of human cytokines dramatically improves reconstitution of specific human-blood lineage cells in humanized mice. Proc Natl Acad Sci U S A. 2009;106:21783-8.

\section{Submit your next manuscript to BioMed Central and take full advantage of:}

- Convenient online submission

- Thorough peer review

- No space constraints or color figure charges

- Immediate publication on acceptance

- Inclusion in PubMed, CAS, Scopus and Google Scholar

- Research which is freely available for redistribution

Submit your manuscript at www.biomedcentral.com/submit
C Biomed Central 